\title{
Homofobia e Preconceito contra Diversidade Sexual: Debate Conceitual
}

\author{
Ângelo Brandelli Costa ${ }^{1}$ \\ Henrique Caetano Nardi \\ Instituto de Psicologia da Universidade Federal do Rio Grande do Sul, \\ Porto Alegre, RS, Brasil
}

\begin{abstract}
Resumo
O termo homofobia tem sido amplamente utilizado para a conceitualização do preconceito e discriminação contra indivíduos que apresentem orientação sexual diferente da heterossexual. Apesar do seu uso corrente no Brasil, são quase ignoradas a extensa discussão e as controvérsias teóricas em torno do termo desde que foi cunhado na década de 1970 nos Estados Unidos. Esse estudo discutirá o surgimento do conceito homofobia, seus empregos, limites, possibilidades e implicações teóricas. Também abordará as reinterpretações da ideia de homofobia a partir da psicologia social à luz dos conceitos de preconceito e, por extensão, de atitudes. Por fim, defender-se-á o uso da construção "preconceito contra diversidade sexual" como alternativa à homofobia para melhor definir o fenômeno quando pensado do ponto de vista individual.
\end{abstract}

Palavras-chave: Homofobia, Psicologia Social, preconceito contra diversidade sexual.

\section{Homophobia and Prejudice against Sexual Diversity: Conceptual Debate}

\begin{abstract}
The term homophobia has been widely used for the conceptualization of violence and discrimination against individuals who have different sexual orientation from heterosexual. Despite its current use, it is almost ignored, especially in Brazil, the extensive theoretical discussion and controversy around the term since it was coined in the 1970 in the USA. This study discusses the emergence of the term homophobia its uses, limits, possibilities and theoretical implications. It will also addresses the reinterpretations of the idea of homophobia by social psychology using the concept of prejudice and per extent attitudes. Finally, it is defended the use of the construction "prejudice against sexual diversity" as an alternative to homophobia to better define the phenomenon in the individual point of view.
\end{abstract}

Keywords: Homophobia, Social Psychology, prejudice against sexual diversity.

\section{Homofobia y Prejuicio contra Diversidad Sexual: Debate Conceptual}

\section{Resumen}

El término homofobia se ha utilizado ampliamente para la conceptualización de la violencia y la discriminación contra las personas con orientación sexual distinta de la heterosexual. A pesar de su uso actual,

Endereço para correspondência: Rua Ramiro Barcelos, 2600, Bairro Santa Cecília, Porto Alegre, RS, Brasil 90035-003. E-mail: brandelli.costa@ufrgs.bre hcnardi@gmail.com

Apoio financeiro: Coordenação de Aperfeiçoamento de Pessoal de Nível Superior (CAPES), Conselho Nacional de Desenvolvimento Científico e Tecnológico (CNPq). 
son casi ignorados el amplio debate teórico y la controversia en torno a la palabra desde que fue acuñada en la década de 1970 en los Estados Unidos. Este estudio analizará el surgimiento del concepto homofobia sus empleos, límites, posibilidades e implicaciones teóricas. También se abordará reinterpretaciones de la idea de homofobia a la luz de los conceptos prejuicio y, por extensión de actitudes. Por último, se va a defender el uso de la construcción "prejuicio contra diversidad sexual" como una alternativa para definir mejor el fenómeno cuando pensado de punto de vista individual.

Palabras clave: Homofobia, Psicología Social, prejuicio contra diversidad sexual.

O termo homofobia tem sido amplamente utilizado para a conceitualização da violência e discriminação contra indivíduos que apresentem orientação sexual diferente da heterossexual, especialmente no Brasil (por exemplo: Junqueira, 2007; Prado \& Machado 2008). Não é difícil constatar que homofobia já faz parte do vernáculo popular e acadêmico e figura na imprensa nacional em quase todas as discussões sobre o tema (Possamai \& Nunes, 2012). A própria política de combate ao preconceito contra orientação sexual e identidade de gênero lançada em 2004 pelo governo brasileiro tem como título Brasil sem Homofobia, o mesmo ocorre com outras políticas e programas que a seguiram (Mello, Brito, \& Maroja, 2012).

Apesar do seu uso, são quase ignoradas, no Brasil, a extensa discussão e as controvérsias teóricas em torno do termo desde que foi cunhado na década de 1970 nos Estados Unidos (Fernandes, 2012). O que é a homofobia, afinal? Uma patologia? Uma atitude? Um modo particular de ver o mundo? Um traço de personalidade? A homofobia é um fenômeno individual, coletivo, institucional? Trata-se de uma questão política, cultural, histórica, psicológica, sociológica, psiquiátrica? Portanto, do ponto de vista da pesquisa acadêmica e da precisão conceitual é necessário perguntar: ainda é válido empregar o conceito de homofobia? Com seu caráter polissêmico, que potencialidades e limites apresenta frente a diferentes abordagens? O conceito é suficientemente preciso para produzir os efeitos dele esperados? O conceito de homofobia deveria ser ressignificado, abandonado, substituído ou, quem sabe, ser pensado em conjunto com outros conceitos? (Junqueira, 2007).

Buscando responder a essas questões, esse texto será dividido em duas partes. Na primeira, descrevem-se o surgimento do conceito homofo- bia, seus empregos, limites, possibilidades e implicações teóricas. Na segunda parte, são abordadas as reinterpretações da ideia de homofobia produzidas pela psicologia social no contexto anglo-saxão, sobretudo, na sua vertente norte-americana à luz dos conceitos de preconceito e, por extensão, de atitudes. Por fim, será defendido o uso da construção "preconceito contra diversidade sexual" como alternativa à homofobia para melhor definir o fenômeno quando pensado do ponto de vista individual.

\section{Do Surgimento ao "Fim" da Homofobia}

Historicamente, a psicologia teve um papel central na legitimação e na perpetuação do estigma relacionado às orientações não heterossexuais (Gilman, 1985). Boa parte do século XX testemunhou à interpretação dominante da psicologia e da psiquiatria a respeito da homossexualidade, a qual se fez presente nas duas primeiras edições do manual diagnóstico de doenças psiquiátricas da American Psychiatric Association (APA). Nelas, "homossexualismo" figurava primeiro como um transtorno de personalidade e em seguida como um transtorno de identidade sexual. Variados problemas foram descritos nas pesquisas que supostamente apoiavam a noção da homossexualidade como patologia, incluindo falta de clareza conceitual, classificação inadequada dos participantes, grupos de comparação inadequados, amostragem falha, não observância de fatores sociais possivelmente correlacionados e uso de medidas questionáveis (Gonsiorek, 1991). Infelizmente, essas pesquisas foram por muito tempo ignoradas e as orientações não heterossexuais acriticamente patologizadas até meados da década de 1970. No entanto, o maior catalisador para a mudança no estatuto diagnós- 
tico da homossexualidade não foi o pretenso avanço científico, mas o ativismo político (Drescher, 2010).

Os esforços políticos para promover os direitos dos homossexuais remontam a Europa do século XIX (Greenberg, 1988). Contudo, foi no período posterior à Segunda Guerra Mundial, nos EUA, que grupos se organizaram para contestar a discriminação, embora de maneira discreta e pouco intrusiva. Em 1969, um incidente violento entre a polícia e os/as frequentadores/as gays e travestis de um bar em Nova York, chamado Stonewall, iniciou uma nova fase do ativismo. Acontecimentos semelhantes emergiram na esteira dos eventos de maio de 1968, na Europa, apontando para uma militância visível. Esta transformação de um modo de ser homossexual pré e pós Stonewall aponta para dois modelos de afirmação da sexualidade, uma a ser vivida no espaço privado (no armário) e outra que propõe uma afirmação política das sexualidades não heterossexuais no espaço público (Chauncey, 2002). O movimento que ganhava força confrontava os tradicionais estereótipos associados à homossexualidade. No lugar de buscar serem tratados como minoria, tais grupos buscavam repensar a forma como era entendida/construída a sexualidade e seu lugar na sociedade (Greenberg, 1988). Esse novo ativismo logo percebeu que as teorias psicológicas, psiquiátricas e psicanalíticas em torno da homossexualidade contribuíam para a manutenção do estigma. Passando da contestação à ação, ativistas participaram das reuniões da APA mostrando o sofrimento psíquico decorrente do estigma que era reforçado pelas categorias diagnósticas psiquiátricas (Marcus, 1992). Esse embate entre ativismo político e o establishment psiquiátrico e psicológico norte-americano culminou na mudança no estatuto diagnóstico da homossexualidade.

Em 1973, a APA removeu o "homossexualismo" da terceira edição do seu manual diagnóstico de doenças mentais (DSM III), em virtude da falta de bases empíricas que associassem a homossexualidade a indicadores de transtornos psicológicos e devido às pressões do movimento pelos direitos sexuais LGBT (lésbicas, gays, bissexuais e travestis/transexuais). No momento em que a homossexualidade deixa de ser tomada como um problema de saúde, as discussões nesse campo recaem sobre aqueles que a consideram um desvio. George Weinberg publica, em 1972, Society and the Healthy Homosexual (A Sociedade e o Homossexual Saudável), introduzindo o conceito homofobia: "Homofobia é o pavor de estar próximo a homossexuais - e no caso dos próprios homossexuais, autoaversão" (Weinberg, 1972, p. 8). O livro popularizou o termo e introduziu o preconceito contra orientação sexual como um problema acadêmico digno de análise e intervenção. O projeto de Weinberg tinha duplo sentido, a preocupação política (mais que teórica) em fornecer ferramentas de luta para o movimento gay da época e, também, a de situar a discriminação contra homossexuais no campo da patologia, via a ideia de fobia (Herek, 2004). "Eu nunca consideraria um paciente curado caso não superasse seu preconceito contra homossexuais", escreveu Weinberg (1972, p. 1), invertendo dessa forma a distinção que até então opunha de um lado o "homossexual desajustado" e de outro a "sociedade normal". O termo rapidamente ganhou popularidade, passou a ser de uso corriqueiro no ativismo político e representou um avanço na reivindicação por direitos de populações LGBT, assim como na compreensão do preconceito a que essas populações foram submetidas.

No entanto, a ideia de homofobia não logrou somente méritos. Um claro exemplo foi seu uso no sistema judiciário norte-americano. Historicamente, as práticas judiciárias e os júris enviesados não mitigaram os crimes anti-homossexuais, pelo contrário, perpetuaram o ciclo de violência e abuso (Harvard Law Review [HLR], 1990). O advento da ideia de homofobia cronificou essa situação. Muitas cortes permitiram aos/às perpetradores/as de violência anti-homossexual reivindicar que suas ações se deviam a transtornos psicológicos via ideia de homofobia e/ou via um "pânico homossexual" proveniente de uma homossexualidade latente e reprimida. Mesmo nos casos em que faltava um claro apontamento de que o acusado cometeu um crime com base no pânico homossexual, a mera admissão da orientação sexual da vítima nor- 
malmente resultava em leniência (HLR, 1990). Sustentando-se na proposição teórica de que o medo e o ódio a um/a homossexual não eram determinados por uma volição, convencionou-se a ideia da falta de controle para violência anti-homossexual. A aceitação da homofobia como um uma doença mental diminuiu a responsabilidade individual para as consequências do preconceito e reconheceu o comportamento discriminatório como imutável e inevitável, portanto encorajando sua recorrência.

Outros problemas teóricos rapidamente emergiram. Em primeiro lugar, o reconhecimento de que a homossexualidade, mesmo em estado latente, não constituía uma doença, fez com que a ideia de pânico homossexual perdesse força. Uma vez que não haveria um desajuste inerente à homossexualidade, não se justificaria psicologicamente a perda do juízo proveniente de uma homossexualidade reprimida por parte do agressor. Em segundo lugar, estudos demonstraram que a homofobia não era uma doença, mas um preconceito. Apesar de já haver apontamentos teóricos anteriores, Logan (1996), em um estudo que investigava a natureza das respostas anti-homossexuais, constatou empiricamente pouca, se é que alguma, evidência em prol da caracterização dessas respostas como fóbicas. Através de um questionário de atitudes em relação a homens e mulheres homossexuais, estudantes universitários foram avaliados quanto a suas atitudes, se fóbicas ou preconceituosas. Como a maioria das respostas não foi classificada como fóbica, o autor concluiu que as atitudes anti-homossexuais precisavam ser teorizadas a partir da psicologia do preconceito e não da psicopatologia. Portanto, o termo homofobia se mostrava outra vez inadequado conceitualmente para designar o preconceito contra homossexuais.

A homofobia também foi alvo de críticas políticas. Uma dessas ressalvas sugeriu que, se o preconceito fosse considerado uma resposta incontrolável, o/a homofóbico/a tenderia a ser visto/a menos como agressor/a e mais como vítima dos/as homossexuais (que para resolver o problema, deveriam permanecer ocultos/as, se não deixar de existir). Ou seja, a ideia de homofobia faria com que o ônus do preconceito reca- ísse sobre a vítima (os/as homossexuais) e não sobre o/a agressor/a. Outra ressalva era a de que a homofobia tornaria o preconceito uma patologia de indivíduos específicos que desviariam de uma sociedade supostamente igualitária, obscurecendo a análise do preconceito como um problema enraizado na estrutura da sociedade. $\mathrm{Ou}$ seja, a homofobia individualizaria um problema que também é social (Wickberg, 2000). Na esteira dessas críticas, outros termos surgiram para dar conta do fenômeno do preconceito; dentre os mais citados estão heterossexismo e heteronormatividade.

O heterossexismo não tem origem nem definição precisas. Herek (2004) aponta que o termo teria sido criado no interior do movimento pela ampliação dos direitos civis, na década de 1970, a partir das ideias de racismo e sexismo. Heterossexismo por vezes é utilizado como sinônimo de homofobia, porém parece oferecer uma explicação mais sociológica, remetendo o preconceito à estrutura institucional, material e ideológica da sociedade. Herek (2004) fornece uma visão mais precisa do construto, afirmando que o heterossexismo se refere à manifestação e à perpetuação, em instituições como a justiça, a educação e o trabalho, da ideia de que tudo que não é heterossexual tem menos valor e legitimidade. É o heterossexismo que cria as condições para as manifestações da homofobia (Pharr, 1997). Como o heterossexismo é uma prática institucional que discrimina mesmo quando não há uma intenção de indivíduos isolados ao preconceito, uma análise a partir desse ponto de vista permite, por exemplo, perceber a origem do preconceito indireto, como as leis que excluem populações não heterossexuais por omissão.

O termo heteronormatividade, por sua vez, foi criado por Michael Warner na década de 1990 para definir o sistema de ideias que estabelece a heterossexualidade como norma. Segundo essa perspectiva, a partir dos sexos biológicos (macho, fêmea) se convencionaram expressões de gênero (masculina, feminina), das quais derivariam orientações sexuais (hetero/homossexual). Ou seja, há a imposição de uma linearidade/congruência entre sexo biológico, gênero e orientação sexual, sendo que essas categorias mantêm 
uma relação de necessidade e complementaridade umas com as outras. O autor vai além, sustentando que a inteligibilidade do humano passa pela afirmação da heterossexualidade (Warner, 1993). Tendo como foco a análise discursiva, Warner defende existir uma oposição entre heterossexualidade e homossexualidade, ou seja, por se constituir em oposição à homossexualidade, a heterossexualidade é automaticamente anti-homossexual. Nesse caso, a solução apontada seria a transgressão de tais polos, descontruindo essas duas noções.

Em resumo, numa tentativa de conciliar tais visões por vezes contraditórias, seguindo a proposta de Herek $(2004,2007)$ pode se dizer que em um primeiro nível, mais próximo da ideia de heteronormatividade, o preconceito se manifesta no conhecimento compartilhado que desqualifica sexualidades, identidades, comportamentos e comunidades não heterossexuais, demarcando grupos sociais e valorando diferentemente esses grupos e seus membros. Um segundo nível, se expressa na estrutura da sociedade, nas relações de poder e instituições, por exemplo, negando o acesso a direitos fundamentais à população LGBT. Esse nível corresponde ao que se tem definido como heterossexismo. Por fim, os indivíduos são formados a partir desses modelos e, por meio de suas atitudes e crenças, os reforçam, constituindo o terceiro nível, que pode ser denominado preconceito contra diversidade sexual (Tabela 1).

\section{Tabela 1}

\section{Modelos Teóricos}

\begin{tabular}{cc}
\hline Conceito & Unidade de Análise \\
\hline Heteronormatividade & Discursos \\
Heterossexismo & Estrutura Social \\
$\begin{array}{c}\text { Preconceito contra } \\
\text { diversidade sexual }\end{array}$ & Atitudes \\
\hline
\end{tabular}

Nota. Baseada em Adam (1998).

Percebe-se, portanto que homofobia (agora preconceito contra diversidade sexual), heterossexismo e heteronormatividade não são excludentes e oferecem explicações e possibilidade de intervenções em níveis distintos de análise.
Como demonstrando na tipologia proposta, não se pode perder de vista que o preconceito é simultaneamente um fenômeno social e individual. Cada perspectiva pode, independentemente, oferecer insights valiosos a respeito da natureza do preconceito sem ser redutível a um nível mais fundamental ou superior de análise. Como afirmou Gordon Allport (1954), a causação plural do preconceito, é a primeira lição que se deve ter em mente.

É importante ressaltar que a "internalização" das dinâmicas sociais que desqualificam a diversidade sexual também acontece com as pessoas não-heterossexuais. A ideia de estresse de minoria (minority stress), discute esse caso (Meyer, 2003). Essa teoria postula que a discriminação sofrida como resultado de pertencer a um grupo socialmente desfavorecido leva a resultados adversos para a saúde. Esses resultados adversos são oriundos do acúmulo de estressores sociais, geralmente conceitualizados como: (a) a experiência direta de rejeição ou violência como resultado da orientação sexual; (b) a construção da própria identidade a partir das atitudes negativas da sociedade em relação à diversidade sexual; (c) a antecipação do preconceito, que está associada, por exemplo, a ocultação da orientação sexual. Embora a leitura contemporânea esteja dando grande ênfase para o preconceito do ponto de vista das vítimas, objetivo desse artigo, como já exposto, é analisar o dinâmica do preconceito do ponto de vista dos agressores.

\section{O Preconceito contra Diversidade Sexual}

Como foi exposto, o conceito homofobia foi gradativamente perdendo força e sendo reconceitualizado a partir da psicologia do preconceito. Portanto, de forma a definir de maneira mais precisa o preconceito contra diversidade sexual é necessário retomar, a partir da psicologia social, sobretudo norte-americana, o conceito de preconceito e, por extensão, de atitudes.

Gordon Allport (1954), em sua obra The Nature of Prejudice, fez a primeira abordagem sistemática do preconceito descrevendo-o como atitudes adversas ou hostis em relação a uma 
pessoa que pertence a um grupo, simplesmente porque pertence a esse grupo, presumindo-se assim que ela possui as características contestáveis a ele atribuídas. Contemporaneamente, outras definições são utilizadas, embora guardem em relação à definição clássica a ideia de atitude: o preconceito é uma atitude (tanto positiva quanto negativa) em direção a um grupo ou seus membros que cria ou mantém uma relação de status hierárquica (Dovidio, Hewstone, Gilck, \& Esses, 2010). Atitude é um conceito que se confunde com a própria história da psicologia social (Farr, 2002). Ele já figurava nos primeiros escritos de Thurstone e Allport no início do século XX, e apesar de diversas críticas e reformulações recebidas, segue em uso por ser útil para sumarizar a avaliação a respeito de outra pessoa, de si mesmo, objetos, ações, eventos, ideias, etc.

A literatura consagrou a definição de atitude do The Psychology of Atitudes de Eagly e Chaiken (1993). Os autores definem atitude como uma tendência psicológica que se expressa em uma avaliação favorável ou desfavorável de uma entidade específica. Disso decorrem alguns consensos: (a) Atitude é uma tendência psicológica, ou seja, é um estado com alguma estabilidade temporal, diferentemente da personalidade, que seria mais estável, ou dos estados emocionais, que seriam passageiros. (b) As atitudes são aprendidas e, portanto, modificáveis. (c) A atitude é uma resposta avaliativa. Admiração seria o extremo da atitude positiva. O preconceito seria o extremo de uma atitude negativa. (d) Atitude é um construto hipotético, isso indica que as atitudes não são diretamente observáveis. Trata-se, portanto, de uma inferência sobre os processos psicológicos de um indivíduo, a partir de observações dos seus comportamentos, de suas crenças e de seus afetos. Em suma, atitude é uma organização relativamente duradoura de crenças, dotada de carga afetiva pró ou contra um objeto definido, que predispõe a uma ação (Vala \& Monteiro, 2004).

As atitudes são compostas por afetos, comportamentos e crenças. Embora para muitos estudiosos a evocação dessas dimensões não seja necessária, já que o termo atitude as englobaria, elas são úteis para análise (Brown, 2010). Cren- ças são os aspectos cognitivos, aquilo que se pensa, a respeito do objeto atitudinal. Alguém pode acreditar que homossexuais não devam ser professores do ensino fundamental. Essa crença constitui uma informação cognitiva que compõe a atitude em relação às orientações não-heterossexuais. O componente afetivo das atitudes trata daquilo que se sente em relação ao objeto, as sensações e as emoções que o objeto evoca; por exemplo, experienciar raiva ou repulsa quando se está com homossexuais. Comportamentos compreendem as interações, incluindo prévias e futuras, com o objeto atitudinal. $\mathrm{O}$ fato de que alguém não selecionaria um candidato homossexual em uma entrevista de emprego constitui uma informação comportamental importante a respeito da atitude em relação às orientações não heterossexuais.

A atitude descrita anteriormente, retomando a definição de Dovidio et al. (2010), pode ser descrita como preconceito. Ela é composta de uma crença negativa e generalizante (estereótipo), um afeto negativo e um comportamento negativo (discriminação; Figura 1).

Comecemos investigando os aspectos cognitivos do preconceito, os estereótipos. Allport (1954) considerou o ato de estereotipar uma tendência sui generis do pensamento. Dada nossa limitada capacidade de processar informações, adotamos estratégias que simplificam problemas complexos. Fazemos isso ora negligenciando algumas informações para reduzir o excesso, ora utilizando outras em demasia para não ter de procurar por novas. Por exemplo, se pensarmos em Juliano, 24 anos, médico veterinário, morador de Porto Alegre, de origem alemã e homossexual; mesmo sem conhecermos a pessoa em questão, certamente, muitas imagens relativas à homossexualidade, origem alemã, morador de Porto Alegre, médico veterinário e jovem se farão presentes em nossa mente. Quando interagirmos com Juliano, a interação tende a ser mediada menos pelas características individuais do jovem do que pelas categorias e todas as informações que já foram recebidas a respeito delas. Assim, para determinados grupos sociais, médicos veterinários podem ser vistos como extremamente respeitáveis e, por consequência, 


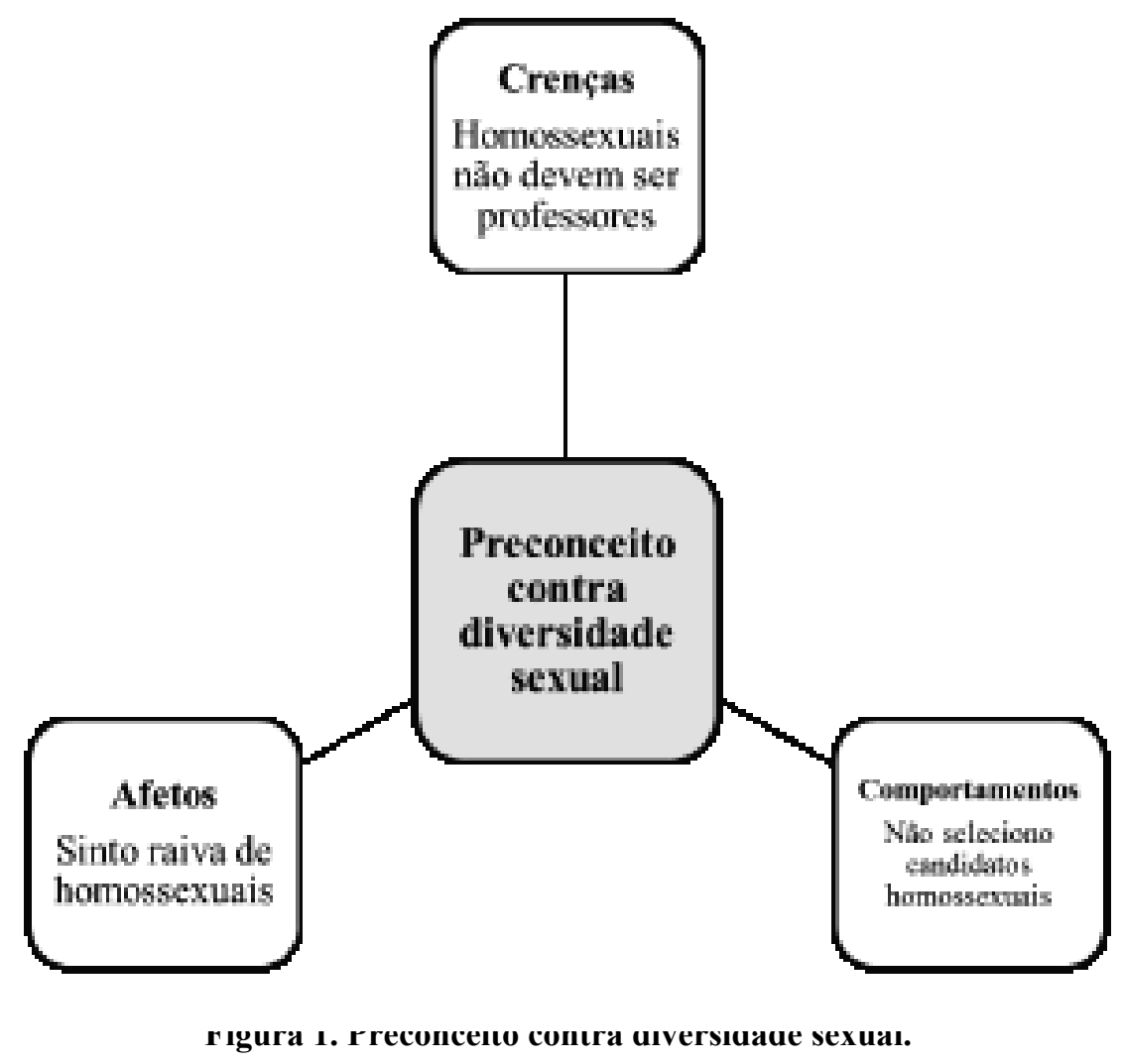

essa será impressão de Juliano. O estereótipo se refere justamente a essas qualidades percebidas que suspostamente refletem um indivíduo ou um grupo (Dovidio et al., 2010).

Esse tipo de categorização não é em si o preconceito, mas lhe dá fundamentos. O preconceito se forma graças aos estereótipos presentes em determinadas culturas, que muitas vezes servem para justificar e manter desigualdades sociais. Por exemplo, um estereótipo construído culturalmente e associado aos negros nos Estados Unidos é o crime. Por isso, pessoas brancas associam mais rapidamente situações relacionadas ao crime quando encontram com uma pessoa negra (Smith \& Makie, 2000), o que traz implicações relevantes para o cotidiano daquele país. No caso das orientações não heterossexuais, um estudo mostrou o papel dos estereótipos na manutenção do preconceito através da técnica do júri simulado para investigar a culpa atribuída à vítima em casos de crimes motivados por orientação sexual (Plumm, Terrance, Henderson, \& Ellingson, 2010). Quanto mais negativas as atitudes do júri em relação a orientações não heterossexuais, maior foi a atribuição de culpa à vítima, quando ela era homossexual.
Muitos instrumentos foram desenvolvidos para avaliar o componente cognitivo do preconceito. No caso do preconceito contra diversidade sexual, o Homophobia Scale, Attitudes Toward Homosexuality Scale, Index of Homophobia, entre outros identificados por Costa, Bandeira e Nardi (2013) e Schawanberg (1993). Esses instrumentos partem do princípio de que o preconceito pode ser acessado por meio de autorrelato do posicionamento individual. Eles apresentam afirmações do tipo "se eu visse dois homens de mãos dadas em público eu me sentiria perturbado" onde o entrevistado deve marcar se concorda ou não. É importante observar como esses itens são construídos a partir de estereótipos presentes e determinadas culturas e épocas e, portanto, precisam de revisões constantes. Por exemplo, uma das primeiras versões da Attitudes Toward Gays and Lesbians Scale (ATLG) continha itens como: "aos homens homossexuais não deveria ser permitido lecionar em escolas primárias e secundárias" e, "as leis estaduais que regulam o comportamento sexual privado e consentido entre mulheres lésbicas deveriam ser modificadas" (Herek, 1987). Com se percebe, esses são itens que dizem respeito ao contexto norte-americano 
dos anos 80 e 90 . No Brasil, esse tipo de preconceito se manifesta de outras maneiras. Historicamente, a homossexualidade no Brasil foi caracterizada pelas expressões de gênero vinculadas aos papéis sexuais (o bofe, um homem masculino ativo sexualmente; e a bicha, um homem feminino e passivo sexualmente; Fry, 1986). Com a organização do movimento social em torno da luta contra a epidemia de AIDS nos anos 90, influenciados pela cultura norte-americana, o modelo bicha-bofe mudou, e os homens que fazem sexo com homens passaram ser descrito como 〈gay), independentemente de papéis sexuais (Green, 1999). No entanto, os aspectos do modelo tradicional mantiveram-se, e até hoje homens gays "masculinos", que muitas vezes se consideram e são considerados heterossexuais, estão mais protegidos do preconceito (Parker, 1999). Recentemente, Costa, Peroni, Bandeira, e Nardi (2013) reuniram evidência empírica apontando para o papel central das normas de gênero na manifestação de preconceito contra diversidade sexual no Brasil.

No entanto, essas técnicas de autorrelato apresentam algumas limitações. Por exemplo, não é possível saber se as respostas a essas técnicas são genuínas ou se o entrevistado tentou passar uma boa imagem de si, agradável ao entrevistador (Vala \& Monteiro, 2004). Outra limitação é oriunda do trabalho de LaPiere (1934) em um estudo clássico. O autor viajou pelos EUA acompanhado de um casal de chineses, registrando as reações dos funcionários de diversos restaurantes e hotéis pelos quais passaram. $\mathrm{O}$ grupo foi recusado em apenas um dentre mais de 200 locais. Algum tempo depois, LaPiere enviou uma carta a cada um desses estabelecimentos, perguntando se aceitariam chineses como clientes. Das respostas recebidas, $92 \%$ foram negativas. Esses resultados mostraram que há uma discrepância a ser considerada entre os componentes cognitivos e comportamentais do preconceito. $\mathrm{O}$ trabalho de LaPiere é um exemplo de investigação da discriminação, o aspecto comportamental do preconceito. LaPiere demonstrou em seu estudo que as crenças preconceituosas nem sempre geram atos hostis. O contrário também ocorre. No caso da ideia de heterossexismo, como visto an- teriormente, o preconceito pode ser institucional e não oriundo do comportamento discriminatório individual; embora o comportamento individual se legitime a partir do plano institucional, uma vez que a tendência é que aquelas pessoas que apresentem crenças negativas se comportem de maneira discriminatória (Smith \& Makie, 2000). Em outro estudo do aspecto comportamental do preconceito (Gabriel \& Banse, 2006), os participantes receberam uma chamada por engano de um homem que se identificava em algumas situações como heterossexual e em outras como homossexual. Informando que seu carro havia quebrado e que estava sem dinheiro para pagar outra ligação, o homem pedia que os participantes da pesquisa telefonassem por ele para seu namorado ou sua namorada, dependendo do caso. Os resultados de diversos países são consistentes em mostrar que homossexuais foram menos ajudados do que heterossexuais.

Embora possamos avaliar o preconceito por meio de nossas crenças e comportamentos, as respostas emocionais podem ser mais fidedignas, já que, na maioria das vezes, são expressões involuntárias de nossas atitudes. $\mathrm{O}$ corar da face, $\mathrm{o}$ suor das mãos, o coração bater mais depressa são respostas espontâneas a estados emocionais extremos que podem ser ativados pelo preconceito. Algumas técnicas foram desenvolvidas para avaliar isoladamente os componentes afetivos do preconceito. Um estudo investigou reações espontâneas associadas ao preconceito contra diversidade sexual através de medidas psicofisiológicas como condutância de pele, eletromiograma facial e frequência cardíaca quando participantes da pesquisa eram expostos a imagens de conteúdo homossexual e a estímulos neutros (Lasaitis, 2009). O estudo encontrou altas correlações entre essas respostas e as medidas cognitivas de preconceito. Outro estudo utilizou uma técnica menos ortodoxa para avaliar a relação entre o desejo homossexual e as atitudes negativas em relação a orientações não heterossexuais. Homens autodeclarados heterossexuais foram expostos a estímulos eróticos homossexuais e tiveram as mudanças na circunferência peniana monitoradas. Os participantes mais preconceituosos apresentaram aumento na circunferência 
peniana ao serem expostos a vídeos com estímulos homossexuais explícitos. Ou seja, segundo o estudo, o preconceito está aparentemente associado ao desejo homossexual que os sujeitos negam ou não têm ciência do ponto de vista da representação cognitiva (Adams, Wright, \& Lohr, 1996). A pesquisa citada parece confirmar a tese já rechaçada do "pânico homossexual", ou seja, a impossibilidade de controle individual para a resposta preconceituosa. Na verdade, ela aponta para uma discussão psicanalítica que pressupõe que uma constituição psíquica em contextos culturais marcados pela rejeição social da homossexualidade faz com que indivíduos manifestem uma reação defensiva na forma de preconceito.

Com a definição da homofobia enquanto preconceito, a partir da pesquisa psicológica no contexto anglo-saxão, sobretudo norte-americano, diversos consensos foram construídos a respeito desse preconceito: (a) homens e mulheres têm atitudes similares em relação a mulheres homossexuais, no entanto, homens tendem a ser mais preconceituosos em relação a homens homossexuais; (b) as atitudes preconceituosas favorecem o adoecimento das pessoas que tem como alvo; (c) mulheres tendem a ser menos preconceituosas do que homens; (d) pessoas com idade mais avançada tendem a estigmatizar mais os indivíduos não heterossexuais do que aquelas de meia idade; (e) uma maior escolaridade está associada a um menor grau de preconceito; (f) o preconceito correlaciona-se positivamente com racismo, visão tradicional e estereotipada das expressões de gênero, visão ortodoxa e conservadora da religião e conservadorismo político; (g) pessoas que tiveram contato prévio com indivíduos não heterossexuais tendem a ser menos preconceituosas do que aquelas que nunca tiveram; (h) por fim, a percepção de que os pares manifestam atitudes negativas contribui para manifestações do preconceito (para um apanhado desses estudos: Dovidio et al., 2010; Herek, 2000). No entanto, algumas controvérsias têm se apresentado no debate recente, a partir da tendência que começou a ser percebida ao longo da década de 1990 é a do declínio de declarações preconceituosas públicas, especialmente nas sociedades ocidentais no hemisfério norte.
Diversas pesquisas de base populacional atestaram essas mudanças, mostrando por exemplo que os norte-americanos se tornaram mais liberais em relação à orientação sexual nos últimos 30 anos (Andersen \& Fetner, 2008; Loftus, 2001). No entanto, muitos autores colocaram em questão a univocidade desse processo. Eles afirmam que as mudanças nas normas sociais e o incremento nas legislações antidiscriminação foram o que tornou praticamente inaceitável expressar o preconceito abertamente. Portanto, o que pode estar acontecendo é ocultamente do preconceito e não sua diminuição. Algumas teorias foram desenvolvidas para testar essa hipótese. Uma delas utiliza uma técnica experimental conhecida como bogus pipeline. Nessa técnica, os participantes são conectados por eletrodos na pele a um equipamento que supostamente pode detectar o que eles estão verdadeiramente sentindo. Durante todo experimento, o participante é convencido de que o equipamento é genuíno quando de fato é uma farsa. O experimento consiste em responder a um inventário sobre preconceito sob o escrutínio da máquina. As respostas das pessoas sob a condição pipeline são então comparadas com o grupo que não foi conectado ao falso equipamento. A assunção é de que as pessoas conectadas à máquina serão mais fiéis àquilo que realmente acreditam para não serem pegas de surpresa. De fato, experimentos com essa metodologia têm demonstrado diferenças significativas entre grupos. Um estudo investigando atitudes em relação às orientações não heterossexuais utilizando o bogus pipeline relatou menos preconceito no grupo controle (Boysen, Vogel, \& Madon, 2006).

As pesquisas utilizando o bogus pipeline sugeriram que podemos manter duas atitudes similares sobre o mesmo objeto, uma explícita, passível de ser revelada, e outra implícita. É o contexto e a desejabilidade social - nosso desejo de ser aceitos socialmente - que parecem determinar quais atitudes podem vir à tona. $\mathrm{O}$ Implicit Association Test (IAT) é uma medida de atitudes desenvolvida para detectar o preconceito nessas circunstancias. O IAT foi desenvolvido por Banse, Seise e Zerbe (2001) e avalia atitudes implícitas utilizando os procedimentos de primming. 
O teste avalia a força da associação automática entre conceitos usando uma tarefa de categorização informatizada. Os participantes são cronometrados enquanto associam símbolos representando grupos (p. ex., figuras de casais hetero e homossexuais) a palavras positivas e negativas (p. ex., homossexual + ruim, heterossexual + bom). Nesse tipo de avaliação, pessoas preconceituosas associam mais rapidamente imagens que representam homossexuais a palavras com conotação negativas e imagens representando heterossexuais a palavras positivas e vice-versa.

Outro conjunto de teorias afirma que de fato houve uma mudança social e que ela promoveu alterações na maneira como as pessoas encaram o gênero, a raça e a orientação sexual, por exemplo. Para essas teorias, uma nova forma de preconceito mais simbólica e indireta substitui o "preconceito antigo". Nessa visão, o preconceito moderno não tem a forma de aversão ou de atitude negativa, mas se apresenta de maneira mais ambivalente, inclusive positiva. Muitos homens têm a opinião de que eles são incompletos sem as mulheres ou que mulheres são mais sensíveis do que os homens, ou ainda que uma mulher respeitável deve ser posta em um pedestal. Essas são atitudes positivas que, no entanto, colocam a mulher em uma situação de dependência e, portanto, subordinada em relação aos homens. É dessa forma que o preconceito pode se estabelecer a partir de uma atitude supostamente positiva, porém hierarquizante. $\mathrm{O}$ mesmo ocorre com o preconceito em relação à diversidade sexual. Morrison, Kenny e Harrington (2005) criaram um instrumento para avaliar aquilo que eles chamam de homonegatividade moderna. Para os autores, as objeções clássicas à homossexualidade ligadas à religião, lei e medicina não são mais aplicáveis. A nova escala busca avaliar então crenças como: "homossexuais têm demandas ilegítimas ou desnecessárias para mudar seu status quo" (o direito ao casamento e à adoção); "homossexuais exageram a importância da sua orientação sexual e, por isso, falham em se assimilar à cultura dominante" (a criação das paradas do orgulho); "a discriminação a homossexuais é coisa do passado". Apesar de ser uma hipótese útil, ainda há diversos contextos mais sensíveis às formas antigas de preconceito, e esse parece ser o caso do Brasil (Costa, Peroni, et al., 2013).

\section{Considerações Finais}

A partir dessa reflexão ainda é válido empregar o conceito de homofobia? Cabe ressaltar que, do ponto de vista político, o termo homofobia é potente, apresentando uso corrente na língua, sendo usado para nomear programas governamentais e fomentar o advocacy (Fernandes, 2012). Entretanto do ponto de vista conceitual, a precisão é fundamental, e o termo preconceito contra diversidade sexual parece melhor definir o fenômeno.

É evidente que existem diferentes níveis de análise nos quais o preconceito pode ser estudado e, para uma compressão mais global do fenômeno, certamente, uma abordagem interdisciplinar é necessária. A história nos permite compreender a construção de nossa linguagem e intuições e seu papel no fomento do preconceito, o trabalho de Michel Foucault (1998) é um exemplo disso. A análise jurídica nos permite perceber como um determinado sistema de leis privilegia alguns grupos de indivíduos em detrimento de outros. É o caso do código civil brasileiro que há muito necessita de revisão no que diz respeito às populações LGBTs (Rios, 2011). Uma análise mais sociológica pode mostrar, por exemplo, como os déficits psicológicos que supostamente distinguiam os homossexuais dos heterossexuais eram fruto da grande segregação social e do estigma vivenciado por esse grupo e não de características inatas (Herek, 2010; Meyer, 2003). E na psicologia, conforme exposto no presente estudo, o campo de estudos do preconceito tem sido evocado ao se estudar o preconceito do ponto de vista individual.

A psicologia tem sido mais bem-sucedida em explicar o preconceito do que em alivia-lo. Uma vez que o preconceito é resultado de muitos fatores interacionados, não há uma solução fácil. Muitas dessas soluções já foram aplicadas com algum grau de sucesso com o preconceito racial e de gênero. Estamos em tempo de descobrir se o mesmo se estenderá para a diversidade sexual e essa discussão conceitual pretende contribuir 
para esse processo, uma vez que a precisão conceitual é um elemento fundamental no debate acadêmico.

\section{Referências}

Adam, B. D. (1998). Theorizing homophobia. Sexualities, 1, 387-404. doi:10.1177/13634609800$100-4001$

Adams, H. E., Wright, L. W., \& Lohr, B. A. (1996). Is homophobia associated with homosexual arousal? Journal of Abnormal Psychology, 105, 440-445. doi:10.1037//0021-843X.105.3.440

Allport, G. (1954). The nature of prejudice. Reading, MA: Addison-Wesley.

Andersen, R. A., \& Fetner, T. B. (2008). Cohort differences in tolerance of homosexuality: Attitudinal change in Canada and the United States, 1981-2000. Public Opinion Quarterly, 72, 311330. doi:10.1093/poq/nfn017

Banse, R., Seise, J., \& Zerbes, N. (2001). Implicit attitudes towards homosexuality: Reliability, validity, and controllability of the IAT. Zeitschrift fur Experimentelle Psychologie, 48, 145-160. doi:10.1026//0949-3946.48.2.145

Boysen, G. A., Vogel, D. L., \& Madon, S. (2006). A public versus private administration of the implicit association test. European Journal of Social Psychology, 36, 845-856. doi:10.1002/ ejsp.318

Brown, R. (2010). Prejudice: Its social psychology. Malden, MA: Wiley-Brackwell.

Chauncey, G. (2002). Après Stonewall, le déplacement de la frontière entre le "soi" public et le “soi” privé. L'homosexualité à l'épreuve des representations. Revue Européenne D'histoire Sociale, 3, 45-59.

Costa, A. B., Bandeira, D. R., \& Nardi, H. C. (2013). Systematic review of instruments measuring homophobia and related constructs. Journal of Applied Social Psychology, 43, 1324-1332. doi:10.1111/jasp.12140

Costa, A. B., Peroni, R. O., Bandeira, D. R., \& Nardi, H. C. (2013). Homophobia or sexism? A systematic review of prejudice against nonheterosexual orientation in Brazil. International Journal of Psychology, 458, 900-9009. doi:10.1080/ 00207594.2012 .729839
Dovidio, J., Hewstone, M., Glick, P., \& Esses, V. (2010). The SAGE handbook of prejudice, stereotyping and discrimination. London: Sage.

Drescher, J. (2010). Queer diagnoses: Parallels and contrasts in the history of homosexuality, gender variance, and the diagnostic and statistical manual. Archives of Sexual Behavior, 39(2), 427-460. doi:10.1007/s10508-009-9531-5

Eagly, A., \& Chaiken, S. (1993). The psychology of attitudes. Fort North, PH: Harcourt Brace Javanovich.

Farr, R. (2002). As raízes da psicologia social moderna. Petrópolis, RJ: Vozes.

Fernandes, F. B. M. (2012). Por uma genealogia do conceito homofobia no Brasil: Da luta política LGBT à um campo de governança. Passages de Paris, 7, 97-104.

Foucault, M. (1998). História da sexualidade I: A vontade de saber. Rio de Janeiro, RJ: Graal.

Fry, P. (1986). Male homosexuality and spirit possession in Brazil. Journal of Homosexuality, 11, 137-153.

Gabriel, U., \& Banse, R. (2006). Helping behavior as a subtle measure of discrimination against lesbians and gay men: German data and a comparison across countries. Journal of Applied Social Psychology, 36, 690-707. doi:10.1111/ j.0021-9029.2006.00025.x

Gilman, S. (1985). Difference and pathology: Stereotypes of sexuality, race and madness. Ithaca, NY: Cornell University Press.

Gonsiorek, J. C. (1991). The empirical basis for the demise of the illness model of homosexuality. Homosexuality: Research implications for public policy. In J. C. Gonsiorek \& J. D. Weinrich, Homosexuality: Research implications for public policy (pp. 115-136). Thousand Oaks, CA: Sage.

Green, J. N. (1999). Além do carnaval: A homossexualidade masculina no Brasil do século XX. São Paulo, SP: Editora da Universidade Estadual Paulista Júlio de Mesquita Filho.

Greenberg, D. (1988). The construction of homosexuality. Chicago, IL: University of Chicago Press.

Harvard Law Review. (1990). Sexual orientation and the law. Cambridge, MA: Harvard University press. 
Herek, G. M. (1987). Religious orientation and prejudice: A comparison of racial and sexual attitudes. Personality and Social Psychology Bulletin, 13, 34-44.

Herek, G. M. (2000). The psychology of sexual prejudice. Current Directions in Psychological Science, 9, 19-22. doi:10.1111/1467-8721.00051

Herek, G. M. (2004). Beyond "homophobia": Thinking about sexual prejudice and stigma in the twenty-first century. Sexuality Research \& Social Policy, 1, 6-24. doi:10.1525/srsp.2004.1.2.6

Herek, G. M. (2007). Confronting sexual stigma and prejudice: Theory and practice. Journal of Social Issues, 63, 905-925.

Herek, G. M. (2010). Sexual orientation differences as deficits: Science and stigma in the history of American psychology. Perspectives on Psychological Science, 5, 693-699. doi:10.1177/1745691610388770

Junqueira, R. D. (2007). Homofobia: Limites e possibilidades de um conceito em meio a disputas. Revista Bagoas: Estudos Gays: Gêneros e Sexualidades, 1(1), 1-22.

LaPiere, R. T. (1934). Attitudes versus action. Social Forces, 13, 230-237.

Lasaitis, C. (2009). Aspectos afetivos e cognitivos da homofobia no contexto brasileiro: Um estudo psicofisiologico (Dissertação de mestrado, Universidade Federal de São Paulo, SP, Brasil). Recuperado em http://www.bdtd.unifesp.br/

Loftus, J. (2001). America's liberalization in attitudes toward homosexuality, 1973 to 1998. American Sociological Review, 66, 762-782. doi: $10.2307 / 3088957$

Logan, C. R. (1996). Homophobia? No, homoprejudice. Journal of Homosexuality, 31, 31-53. doi:10.1300/J082v31n03 03

Marcus, E. (1992). Making gay history. New York: Harper.

Mello, L., Brito, W., \& Maroja, D. (2012). Políticas públicas para a população LGBT no Brasil: Notas sobre alcances e possibilidades. Cadernos Pagu, 39, 403-429. doi:10.1590/ S0104-83332012000200014

Meyer, I. H. (2003). Prejudice, social stress, and mental health in lesbian, gay and bisexual populations: Conceptual issues and research evidence. Psychological Bulletin, 129, 674-697. doi:10.1037/0033-2909.129.5.674
Morrison, T. G., Kenny, P., \& Harrington, A. (2005). Modern prejudice toward gay men and lesbian women: Assessing the viability of a measure of modern homonegative attitudes within an Irish context. Genetic, Social, and General Psychology Monographs, 131, 219-250. doi:10.3200/ MONO.131.3.219-250

Parker, R. G. (1999). Beneath the Equator: Cultures of desire, male homosexuality, and emerging gay communities in Brazil. New York: Routledge.

Pharr, S. (1997). Homophobia: A weapon of sexism. Berkeley, CA: Chardon Press.

Plumm, K. M., Terrance, C. A., Henderson, V., \& Ellingson, H. (2010). Victim blame in a hate crime motivated by sexual orientation. Journal of Homosexuality, 57, 267-286. doi:10.1080/00918360903489101

Possamai, P. C., \& Nunes, A. D. C. (2012). O tema da homofobia em dissertações e teses. Métis: História \& Cultura, 10, 273-284.

Prado, M. A., \& Machado, F. V. (2008). Preconceito contra homossexualidades: A hierarquia da invisibilidade. São Paulo, SP: Cortez.

Rios, R. R. (2011). Direitos sexuais, uniões homossexuais e a decisão do Supremo Tribunal Federal (ADPF $n^{\circ}$ 132-RJ e ADI 4.277). In R. R. Rios, C. Golin, \& P. Leivas (Eds.),_Homossexualidade e direitos sexuais: Reflexões a partir da decisão do STF (pp. 69-114). Porto Alegre, RS: Sulina.

Schawanberg, S. L. (1993). Attitudes towards gay man and lesbian woman: Instrumentation issues. Journal of Homosexuality, 1, 99-136. doi:10.1300/J082v26n01_08

Smith, E., \& Mackie, D. (2000). Social psychology. Philadelphia, PA: Psychology Press.

Vala, J., \& Monteiro, M. B. (2004). Psicologia social. Lisboa, Portugal: Fundação Caloúste Gulbenkian.

Warner, M. (1993). Fear of a Queer Planet. Minneapolis, MN: University of Minnesota Press.

Weinberg, G. (1972). Society and the healthy homosexual. New York: St. Martin's Press.

Wickberg, D. (2000). Homophobia: On the cultural history of an idea. Critical Inquiry, 27, 42-57.

Recebido: $31 / 05 / 2012$

$1^{a}$ revisão: 08/08/2014 Aceite final: 10/02/2015 